\title{
Subjective experience of diagnosis and treatment in two adolescents with first-episode schizophrenia
}

\author{
Marianella Abarzúa, ${ }^{1}$ Francisco Venegas, ${ }^{1}$ Ximena Hidalgo ${ }^{2,3}$ \\ ${ }^{1}$ Department of Psychology, University of Chile, Santiago, Chile; ${ }^{2}$ CESMAG University Institution, Pasto, Colombia; \\ ${ }^{3}$ Department of Psychology, Vita-Salute San Raffaele Hospital, Milan, Italy
}

\begin{abstract}
The results of a qualitative study on the subjective experience of two adolescents in treatment for first-episode schizophrenia (FESZ) are presented here. We reconstructed the relevant aspects of the diagnosis and treatment processes based on the elaboration of said experience carried out by the participants. We therefore incorporated the perspective of the patients, family members and psychotherapists. The recovery from FESZ, understood as a positive adaptation to the experience of psychosis, is closely connected with the possibility of the adolescent to re-embark on his/her biographical trajectory. In this sense, the concept of recovery from FESZ increasingly emphasizes the subjective dimension of this process. The aim of the study is to understand the subjective experience of diagnosis and treatment processes from the perspective of two patients with FESZ who received comprehensive treatment in the Chilean public health system, their family members and their psychotherapists. The study performed semi-structured interviews and a qualitative content analysis in order to understand and describe, from their perspectives, the subjective experiences associated with the processes of diagnosis and treatment of FESZ. The inclusion of patients, relatives and psychotherapists allowed complementing the perspectives on the phenomenon under study. The results suggest that the central phenomena of appropriation of FESZ and resistance to the appropriation of FESZ are relevant in the accounts of these two cases. The family's emotional climate associated with the experience of FESZ converge in these phenomena, as well as the participation of the adolescent in the processes of diagnosis and treatment, specifically as these processes favor or hinder an appropriation of the psychopathological experience and this enables the reestablishment of the autobiographical continuity. Appropriation of FESZ seems to rely on future prospects that preserve some possibility of performing prior potentialities and expectations, or at least to adapt them in a tolerable way for the adolescents and their environment. Such findings highlight the relevance of developing interventions that encourage more hopeful future perspectives for individuals facing a first psychotic episode and their families.
\end{abstract}

Key words: Appropriation of psychotic experience; Autobiographical continuity; Qualitative methods.

\section{Introduction}

Globally, schizophrenia is one of the mental health problems that contributes most to the global burden of dis-

Correspondence: Marianella Abarzúa, Department of Psychology, University of Chile, Av. Capitán Ignacio Carrera Pinto 1045, Ñuñoa, Santiago, Chile.

Tel: +56.2.29787878

E-mail: mabarzuac@u.uchile.cl

Citation: Abarzúa, M., Venegas, F., \& Hidalgo, X. (2016). Subjective experience of diagnosis and treatment in two adolescents with first-episode schizophrenia. Research in Psychotherapy: Psychopathology, Process and Outcome, 19(1), 58-67. doi: 10.4081/ ripppo.2016.189

Received for publication: 20 July 2015.

Revision received: 20 November 2015.

Accepted for publication: 17 December 2015.

This work is licensed under a Creative Commons Attribution NonCommercial 4.0 License (CC BY-NC 4.0)

(C) Copyright M. Abarzúa et al., 2016

Licensee PAGEPress, Italy

Research in Psychotherapy:

Psychopathology, Process and Outcome 2016; 19:58-67

doi:10.4081/ripppo.2016.189 eases, making it one of the 10 leading causes of disability (Penn, Waldheter, Perkins, Mueser, \& Lieberman, 2005). Consequently, it is a disorder with a high social burden, associated with considerable suffering for patients and their caregivers (Barbato, 1998; Kennedy, Altar, Taylor, Degtiar, \& Hornberger, 2014; Knapp, Mangalore, \& Simon, 2004). The interest in minimizing the social and subjective costs associated to this disorder, has led to the development of specific public policies and mental health programs, to address the need for a comprehensive treatment starting with the first episode of schizophrenia (FESZ) (Barbato, 1998; Dixon, Perkins, \& Calmes, 2009; Gaebel, Riesbeck, \& Wobrock, 2011).

In Chile, schizophrenia provides $1.87 \%$ of total years of life lost to premature death and disability (Ministry of Health, 2009). Its treatment has been a priority of public mental health policies, emphasis stated in the plan that organized the activities in that area during the decade 20002010 (Ministry of Health, 2000) and ratified in the context of the last major health reform, with the addition of FESZ as the first mental health disorder whose treatment was guaranteed by the Law of General Health (Republic of Chile, 2004).

While classical psychopathological traditions have emphasized a pessimistic view regarding the possibility of re- 
covery from schizophrenia (Braehler \& Schwannauer, 2011; Frese, Knight, \& Saks, 2009), the field of clinical research has favored, over the past four decades, the gradual installation of a new therapeutic scenario where recovery from a FESZ emerges as an achievable therapeutic goal (Anthony, 1993; Jenkins \& Carpenter-Song, 2008; Silverstein \& Bellack, 2008). Nowadays, there is a broad consensus regarding the importance of an integral and early intervention of FESZ, as it reduces the risk of recurrence and long-term disability and being critical regarding the possibilities of recovery (Penn et al., 2005; Seikkula, Alakare, \& Aaltonen, 2001). There are several clinical guidelines that provide recommendations for the treatment of FESZ based on the best available knowledge, both internationally (American Psychiatric Association, 2006; Dixon et al., 2009, 2011; Kreyenbuhl, Buchanan, Dickerson, \& Dixon, 2010; Lehman \& Steinwachs, 1998; NICE, 2014; Royal Australian and New Zealand College of Psychiatrists Team, 2005) and in Chile (Ministry of Health, 2009). They all agree on the need for an integral and early intervention for FESZ, which may combine pharmacological, psychosocial and/or psychotherapeutic interventions (Gleeson, Larsen, \& McGorry, 2003; McGorry, Killackey, \& Yung, 2007; Weiden, Buckley, \& Grody, 2007).

The implementation of public policies specifically aimed at treating FESZ, along with clinical research conducted in the field, has favored the establishment of focuses on certain specific characteristics and clinical needs. We will review some of them, relevant to our research problem.

While the current clinical consensus is conclusive in stating that antipsychotic drugs are the cornerstone of treatment, research on the use of pharmacological treatments in FESZ has yielded certain findings that appear to be in conflict with that assertion: this is a clinical group whose rates of medication adherence are notoriously lower than among patients with longer periods of evolution (Kreyenbuhl et al., 2011; Weiden et al., 2007) and, among them, phenomena of slow response and/or resistance to drug treatment appear more often, even when there is sufficient adherence (Gleeson et al., 2003). In addition, they present further clinical phenomena such as depression, demoralization and self-stigmatization, which could not be addressed by drug therapy and directly affect social isolation and disruption of educational and social goals, negatively affecting the prognosis (Braehler \& Schwannauer, 2011; Gleeson et al., 2003). Therefore, patients treated for FESZ show specific characteristics and clinical needs that exceed the scope of traditional drug treatments and, as such, allow an opening to rethink the concept of recovering from a psychotic episode, historically centered on psychopathological remission.

The new clinical scenario has favored an extension of this concept, placing emphasis on the subjective dimension of the recovery process (Lysaker, Glynn, Wilkniss, \& Silverstein, 2010; Penn, et al., 2005; Salvatore et al., 2012). There is a growing consensus regarding the need to broaden its definition: beyond recovery understood as remission of psychopathology (clinical criteria) or the development of meaningful relationships and social roles (social criteria), there would be a process of psychological recovery, specifically linked to the achievement of an understanding of psychotic experiences and the recovery of a sense of autobiographical continuity (Braehler \& Schwannauer, 2011; Davidson \& Strauss, 1992; Lysaker, Ringer, Maxwell, McGuire, \& Lecomte, 2010). For the adolescent who has a FESZ, the ability to positively adapt to the experience of a psychosis is closely connected with the possibility to re-embark in his/her biographical trajectory (Braehler \& Schwannauer, 2011). In this regard, restoring a stable sense of self is at the core of the recovery process (Davidson \& Strauss, 1992; Harder, 2006, 2007).

Indeed, the way people process their psychotic experience or the recovery style has been linked to a long-term outcome (McGlashan, 1987) and, specifically in FESZ, to avoid the processing of the post-episode emotional impact has been linked to a worse symptomatic outcome and a reduced quality of life (Thompson, McGorry, \& Harrigan, 2003). The subjective dimension of the recovery process has become so important that a series of followup studies in patients with schizophrenia indicate that it regards a dimension that is strongly associated with the achievement of a better quality of life, over and above the indicators of psychopathology: in other words, the subjective experience of recovery is more relevant than the presence of clinically relevant symptoms (Albert et al., 2011; Kukla, Lysaker, \& Roe, 2014; Roe, MashiachEizenberg, \& Lysaker, 2011).

For the purposes of this project, it is important to stress that both the findings of the research on pharmacological treatments in the first episode and the transformation of psychopathological models of schizophrenia, have enabled a clinical reflection that has repositioned the importance of psychotherapy as a component of integral treatment strategies in the first psychotic episode. In this context, psychotherapy is understood as an intervention designed to address the profound and complex psychological processes associated with the recovery from a first psychotic episode, going into the field of understanding the psychotic experience, and the effort to recover an autobiographical continuity and a stable sense of self. Thus understood, we can argue that psychotherapy focuses on addressing the subjective dimension of the recovery process from a psychotic episode.

Internationally, authors linked to the field of research on schizophrenia and other severe psychiatric disorders have emphasized the fact that clinicians and researchers have often overlooked or avoided many aspects of the patient's stories about their experiences of schizophrenia (Flanagan, Davidson, \& Strauss, 2010; Roe \& Lachman, 2005; Strauss, 1989), in favor of emphasizing measuring operationalized variables, quantification and testing rigorous hypothesis (Lieberman, 1989). 
From a conceptual point of view, Roe \& Lachman (2005) have stressed that literature on the subjective experience of severe mental disorders has focused on three major themes: the subject's responses and attitudes to his illness, the degree and nature of insight or awareness of the disease and the experience of the disease as a traumatic event. For the purposes of this study, we understand the subjective experience as the way in which the subject interacts with the psychotic experience and builds his own coping strategies (Strauss, 1989), as a spontaneous struggle (Yip, 2004) that occurs in the processes of treatment and rehabilitation.

Previous studies have investigated the narratives of recovery, both from the perspective of patients (Koenig, Castillo, Blanchet, \& Bouleau, 2011; Larsen, 2004; Thornhill, Clare, \& May, 2004) and incorporating the perspective of patients, their family and health professionals (Karow, Naber, Lambert, \& Moritz, 2012; Noiseux \& Ricard, 2008). Comparatively, the number of studies on subjective experience of the recovery that have included participants with a first psychotic episode has been limited. In accordance with Windell, Norman, Lal, and Malla (2014), it is particularly important to investigate the processes and influences that can promote positive therapeutic outcomes on those patients. According to our review, we found no other published studies that addressed the subjective experience of the processes of diagnosis and treatment in adolescents with FESZ and incorporating the perspectives of patients, families and therapists.

The aim of the study was to develop a comprehensive analysis of the subjective experience of diagnosis and treatment processes, from the perspective of two adolescents receiving integral treatment for FESZ in the Chilean public health system, their family members and their psychotherapists.

\section{Methods}

The study performed a qualitative content analysis based on the Grounded Theory (Strauss \& Corbin, 2002), which is a method to develop a theory from systematically analyzed qualitative data. The analysis of data systematically enables the construction of a group of interrelated categories, by considering three procedures: open coding, which corresponds to the analytical process through which the concepts are identified and their properties and dimensions are discovered; axial coding, which corresponds to the process of linking categories to its subcategories in terms of their properties and dimensions, around the axis of one category; and selective coding, corresponding to the process to integrate and refine the built-up theory (Strauss \& Corbin, 2002).

The current study derives from a previous research (Abarzúa, 2010), which explored the meanings associated with the diagnosis and treatment of the FESZ and their impact on the processes of identity conformation of ado- lescent patients of a Chilean day hospital. The sample of the original study consisted of six adolescents and young people between 15 and 21 years (four men and two women), diagnosed with FESZ, in treatment in a day hospital for adolescents, in the public mental health system of Metropolitan Region, Chile. All the participants were recovering or in a social reintegration phase, in accordance with the clinical evaluation of the clinical team, a relevant criterion for clinical and ethical reasons. Their participation consisted of giving semi-structured in-depth interviews about the experiences associated with the diagnosis and treatment process of FESZ, and included an informed consent procedure, ratified by a family member in the case of minors. Their family members and their psychotherapists were also interviewed. The interviews were tape recorded in order to facilitate transcribing and analyzing the data.

The day hospital where the original study was carried out offered an outpatient treatment program for 14 adolescents who attended the public health system, between 14 and 19 years at the time of admission, referred from other public mental health centers. The adolescents had participated in diagnostic confirmation processes in those centers, so the diagnosis of FESZ was already confirmed at the time of admission to the day hospital. The therapeutic program was conducted by a multidisciplinary team, whose clinical guidelines were based on inputs from community psychiatry and psychoanalysis. One of the core activities of the treatment program was individual psychotherapy, an aspect that was a hallmark compared to other institutions working with people with severe psychiatric disorders. In the day hospital studied, individual psychotherapy was conceived as a key therapeutic activity, as it favored and made possible the elaboration of a psychotic episode, promoting its inclusion in the representational field or, in other words, the historicizing of that life event (Artigas, Cortés, \& Díaz, 2010).

The current study selected two cases that comprised indepth interviews with: case A, the patient, his mother and his psychotherapist; case B, the patient and his psychotherapist (the same as in case A). The inclusion of patients, relatives and psychotherapists allowed to complement the perspectives on the phenomenon under study: while patients are the most qualified to take account of their subjective experience of such processes, close family members are participating observers that contribute to the understanding of their stories, and psychotherapists are key witnesses who can account for the resources and progress achieved by patients (Noiseux \& Ricard, 2008).

The data from participants whose interviews are analyzed in this study are outlined below.

\section{Case A}

Patient: Male, 17 years, Peruvian immigrant, student (doing credit by exams), lower-middle income, with psychiatric hospitalization previous to his treatment in the day 
hospital where he received treatment for 1 year and 6 months. He was discharged from the day hospital five months before the interview, and was in outpatient treatment in another public health center.

Mother: 45 years, Peruvian immigrant, microentrepreneur, lower-middle income.

Psychotherapist: Female, 30 years, Chilean, high income, working from a psychoanalytic framework, six years of clinical experience, five of them with individuals with severe psychiatric disorders.

\section{Case B}

Patient: Male, 21 years, Chilean, unemployed, lowermiddle income, with a psychiatric hospitalization previous to his treatment in the day hospital, where he had been receiving treatment for four years, with intermittent dropouts and re-admissions. Preparing for discharge.

Mother: 36 years, Chilean, saleswoman, lower-middle income. She declined to participate in the study, arguing scheduling difficulties. Due to the family structure it was not possible to include another family member in this case.

Psychotherapist: The same as in case A.
The analysis process applied, sequentially, the three procedures of the Grounded Theory (Strauss \& Corbin, 2002): first, an open coding was carried out in parallel for both cases, from which emerged categories that were grouped hierarchically. Next, an axial coding for each case was carried out and, finally, a process of unique selective coding allowed contrasting the two cases. To ensure the quality of the results, the strategy of triangulation using multiple coders (Krause, 1995) was used. All the researchers (the three authors of this article) participated in the process of qualitative data analysis, to validate the identification and interpretation of the generated categories through intersubjective agreement.

Following is the analysis of the two cases examined. In order to enhance the contrast between the processes experienced in each case, we will directly present the results of the selective coding process. Schemes that synthesize these findings are organized around the central phenomena of Appropriation of FESZ and Resistance to the appropriation of FESZ (Figures 1 and 2, which correspond to case $\mathrm{A}$ and $\mathrm{B}$, respectively). The schemes address the background (Family context, Psychotherapeutic intervention in day hospital and Coping strategies) and implica-

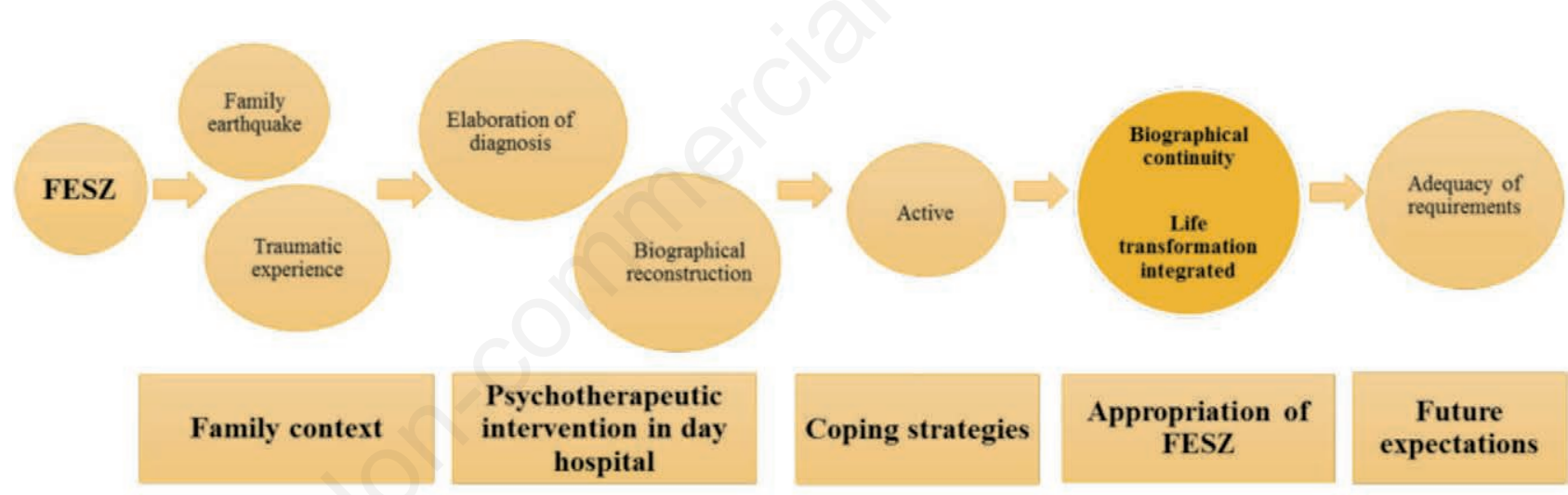

Figure 1. Appropriation of first-episode schizophrenia (case A).

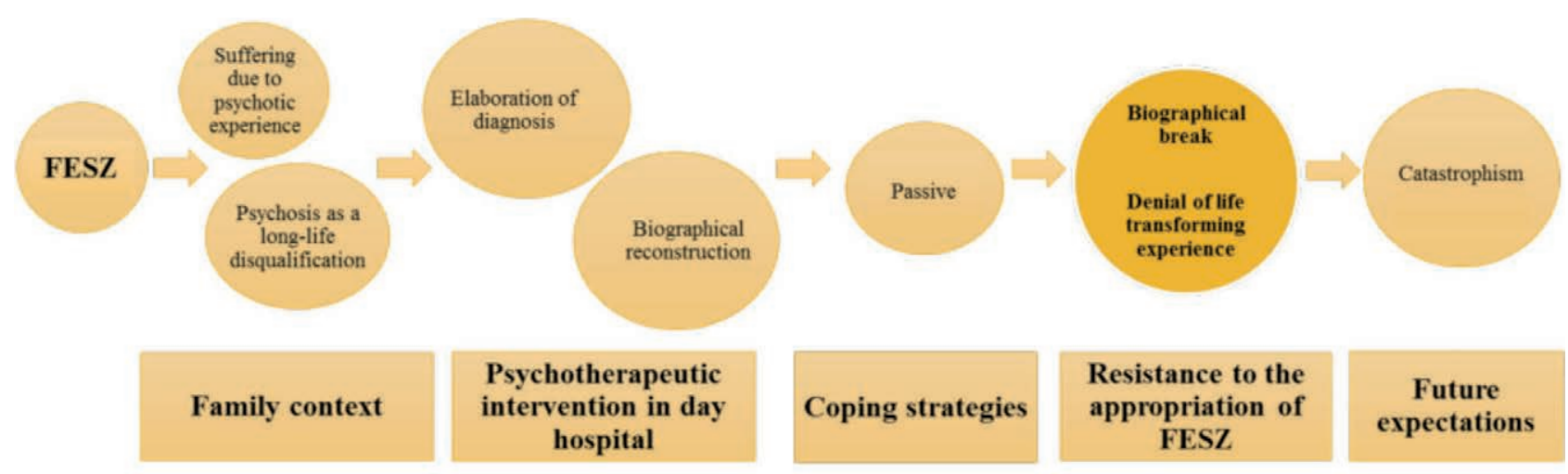

Figure 2. Resistance to the appropriation of first-episode schizophrenia (case B). 
tions of the phenomenon (Future expectations) in each case, and they are accompanied by quotes from the interviews, which have been labeled as $P$ when they come from the patient's interview, $M$ when they come from the mother's interview and $T$ when they come from the psychotherapist's interview. The quotes will favor a contextualized and plausible description of each of the elements of the case analysis.

\section{Results}

\section{Case A}

In the interviews of the case A, concepts appear that are linked to the Family context generated around the experience of FESZ, particularly related to the emotional climate experienced by the family, which was labeled as Family earthquake and Transformation of the son as traumatic experience:

M: It was a shock, like an earthquake for the family, especially for me because I said he had so much, he was such a good student and suddenly everything changed completely and it began slowly, of course it was the disease, it was not his age, it was the disease.

M: A few months later schizophrenia presented itself and it was like traumatic, that is not a healthy child, he is a son I don't know, I didn't recognize his behavior, I said 'This is my son' and he started screaming like a madman, and he wanted to escape.

M: He was like so, so changed, then I saw a child who was si... I mean he was already sick, and he goes almost mad, and I said 'What do I do with my son now? How can I help him and what if I can't?', because I felt as if my hands were tied, How do I act?, because I'm not a psychologist, I am a mom.

Within the process experienced in case A, it appears that the initial perception of the mother was that of a normal child with outstanding skills, not expressing a situation of mental disease. For the mother, the moment when the psychotic episode appears, this creates confusion and surprise (since it is faced as a son I do not know) and she initially fails to understand, because she cannot attribute the chaotic transformation experienced in the family to the changes that occur during adolescence. The mother reports that the situation was like an earthquake, which shows the high level of stress experienced by the family in response to FESZ, as well as the need to seek specialized professional help to cope with the traumatizing experience of the son's transformation.

Regarding the Psychotherapeutic intervention in the day hospital, there are concepts linked to the Elaboration of diagnosis and Biographical reconstruction:

T: There is a name [the diagnosis] to be named and that can be named and it receives a place... and then you can work on it, depending on each patient and [family] system.
T: He [case A] was like more studious, he read, surfed the Internet and after that he came to the sessions to ask 'what is schizophrenia' and it was difficult, because he put so much importance on knowing.

T: So in that way you put together a story from the beginning, because they come for schizophrenia and afterwards you work on the diagnosis, on what happens to them, consciously... so yes, somehow, they have a journey at least for a few years of their lives. I think it also depends on how they elaborate it, but at least in everyone... there is always a question, an interest and a doubt.

T: I think we do work on it and we wonder, I believe that patients like him [case A] who has already done it and has already a whole story of what has happened to him... and now he is fine and he is leading his life normally.

The selected fragments highlight certain aspects addressed by the psychotherapeutic intervention in the day hospital: a diagnosis that is named and elaborated according to the uniqueness of each case, incorporating, for instance, the patient's questions and his/her search for information. The story of the therapist shows that the ability to host these questions and interests favors the building of an account about the psychotic experience and, in case A, takes the form of a story that the patient has about himself and that holds the possibility of leading a normal life.

Around the phenomenon of subjective experience of FESZ, we have grouped three categories: Coping strategies, Modalities of appropriation of FESZ and Future expectations.

Regarding Coping strategies, we will outline two fragments of the patient's interview:

P: First it was at school, there was a psychologist, I didn't feel well, once I left a class because I felt pressured, very anxious and I told the head of the course that I wanted to go to a psychologist because that wasn't normal. And I had already felt that for some time, for like two years, but it had never been that strong.

P: I used to read a lot of books, since I was a child I have read psychology books, some parts, I also once read, when I was older, like 11 or 12 years, a book my brother had brought called 'Enneagram' (...) and I read the whole book and I could identify more with the insane state and I don't know, I said, 'yes, this is me' and that was what was most linked to schizophrenia (...) and that is why I knew about schizophrenia.

In the text of the interview, there are repeated mentions of a patient's active search for information, which started at an early age, even long before he presented symptoms associated with the psychotic episode, which shows his need to understand the discomfort that he experienced. In fact, it was the patient himself who initially sought professional help, performing as an active agent in the disorder and its treatment.

In the Modalities of appropriation of FESZ, case A shows an Appropriation of FESZ, which is expressed in a 
Subjective experience of biographical continuity and Experiences of life transformation integrated:

P: Already since I was young I believed I had schizophrenia, I don't know why, I had some dreams about the future, I don't know (...) and that I was going to have schizophrenia and I thought 'maybe I have schizophrenia'from a very young age, like from when I was 8 ...

P: Before they diagnosed me with schizophrenia I said: 'I'm crazy', and I would start to cry, until when I was 11, I said: 'I'm crazy, what am I going to do now?', but when I was older and they told me I had schizophrenia, I took it well....

P: Before I was diagnosed, like when I was 12, I don't know if I was happier, I don't know, but even though I had voices in my head, but I was and I also had suddenly moments of emptiness, it was ugly, but I think that feeling [the psychotic episode] was worse that a peritonitis operation (...).

P: No [it didn't change my life], but as I said before, when I was younger I was happier, even though I had those feelings of emptiness, I had more convictions about love, love for people and something changed about that.

Within the process experienced by case A, the text shows the experiences before and after the FESZ: the adolescent realizes feelings of anxiety, linked to his difficulties to understand his own mental states in a period of his life, an element that enables a sort of prior awareness of the disease, even before diagnosis (maybe I have schizophrenia). By the time he was diagnosed, it seems to give him a sense of relief to be able to identify the diagnosis, which give him a sense of biographical continuity [I took it well, (my life) did not (change)]. However, the experience of the first episode also introduces certain vital transformations (I was happier, something changed about that), which, in this case, seem to fit into his autobiographical account, without compromising the subjective experience of continuity.

Finally, in relation to Future expectations, there is a story that highlights the Adequacy of requirements:

M: I'm not going to demand anything from him, because

if I demand anything from him he's going to feel uncomfortable and I have to control him, see how he feels in first place, because due to my anxiety to see my son as big, that I want him to study, to become a professional, no, but that, sure, slowly but surely, I understood it at that moment, with a lot more patience that before.

M: I have to teach him to be independent, that slowly but surely he will learn, that if he can't do one thing at a university, because maybe he can't, but a technical subject, and if he doesn't learn to do what I know how to do, making furniture, that he learns to drive, learns how to sell... my son likes doing business.

Within the mother's current projections, the need becomes relevant to adapt her prior requirements and expec- tations about A, which were focused on higher education and becoming a professional. The anxiety that arises in her can be managed on the basis of patience, holding on to the expectation of a future independent life for her son, in any field of work he wants.

\section{Case B}

In interviews of case B there are concepts related to the Family context generated around the experience of FESZ, particularly linked to the emotional climate experienced by the family, who were labeled as Suffering due to psychotic experience and Psychosis as a long-life disqualification:

P: My mother, I wanted to cry every day, I wanted to cry, I don't know, everybody cried, my grandma, my mother, my sister, everybody.

T: For example with him [case B] it happened that, with his mother he came here, and he came with the diagnosis and she said that when they gave her the diagnosis she cried... there wasn 't any history there... so it was really serious for the parents....

T: In fact I remember about him [case B] when he started to study, when we were looking at the subject school, I asked the parents to come separately, the mother separately from the father and I told the father 'all the parents have to support that they study' and he told me 'nobody told me that' [he could study] and this has happened with various parents, so it is as if the diagnosis of schizophrenia disables them forever.

As we can see in case B, the family's emotional climate around the psychotic episode is full of suffering and hopelessness about the future of the son, so that even the therapist of the case affirms that, for the family, schizophrenia is a condition that disables him forever.

Regarding the Psychotherapeutic intervention in the day hospital, even though case B participates in a therapeutic process guided by the same guidelines as case A (that is, directed to favor the process of Diagnosis elaboration and Biographical reconstruction), the story of the therapist suggests some difficulties in the elaboration of the psychotic experience:

T: For example he [case B] arrives and he like settles into schizophrenia, it happened to him, he was elaborating on the pain of the grandfather and the process of 'why me, why does this happen to me', and now he is in the opposition. For example, in the story workshop he told me something... they made a tragic story and it ended happily... and he said 'no, but sometimes you have to live through things that you didn't want to'.

In the perspective of his psychotherapist, B is settled into schizophrenia, emphasizing a depressive emotion associated with that experience. We can hypothesize about the implications that the death of his grandfather had for $\mathrm{B}$, an event that occurred very close to his discharge from psychiatric hospitalization. The impression is as if, for B, asking for elaboration had been twofold: mourning em- 
bedded in the context of a profound life transformation, experienced with suffering.

Around the phenomenon of subjective experience of FESZ, as noted above, we grouped the following categories: Coping strategies, Modalities of appropriation of FESZ and Future expectations. We will elaborate on each of these categories for case B.

Regarding Coping strategies, we will outline two fragments. The second includes a brief interaction patient interviewer, who will be labeled with the letter $\mathrm{E}$, in order to promote an understanding of the context in which the story emerges:

P: No, it's just that I don't know what this disease is... It's something that just came, but in the beginning we thought it was depression, they put it down as depression and really... Schizophrenia.

P: It depends on ... what I... How did I react? When I got the disease? They told me I had schizophrenia ...but I didn't know what schizophrenia was, I didn't know that disease...

E: So, and when they told you that that was the diagnosis, did they also explain what schizophrenia was?

$P$ : No to me, to my mother.

E: And now, someone has explained some more what schizophrenia is?

P: Really, it being a disease that has to do with one intimacy, with one's difficulties...that is all I know.

Coping strategies deal with the experience of a first psychotic episode and are essentially passive. Case B reports the feeling of not feeling part of the diagnostic process. In the interviews there is no mention of a search for information that come up from B's own questions, or the need to understand what was happening to him more actively.

Regarding the Modalities of appropriation of FESZ, case B illustrates the phenomenon of Resistance to the appropriation, resulting in a Subjective experience of biographical break and a Denial of life-transforming experience. Again, quotes include interactions patient interviewer, to make the story intelligible:

E: Do you think that your diagnosis and your treatment have someway influenced the responsibilities you had in your family?

P: No, that was the same, although really I think that if I hadn't gotten ill, I would have finished school some time ago, but as I said all my friends finished school, so...

E: And you put that situation down to your disease....

$P$ : When I remember school I get angry, I get angry and feel powerless, that is why I'm not motivated to continue.

E: If you compare yourself to how you were before you were diagnosed, how would you say you are now, do you see any changes?

$P:$ No, none, in other words, the same, I play Nintendo, I watch $T V$.

E: And do you think that the word schizophrenia, the diagnosis of schizophrenia, do you think it says some- thing about you as a person, does that word in some way reflect you?

P: No, it doesn't reflect me at all.

$E$ : It doesn't reflect you at all...

P: No.

In these quotes we can see the disconnection in the discourse of B in order to integrate the biographical events prior and following FESZ. A resistance to appropriate the psychotic experience can also be seen, both before and after the intervention, even pointing out that the word schizophrenia doesn't reflect me at all. Moreover, it is possible to notice the ambivalence in his speech, saying, on the one hand, that there is no change in his life after the FESZ, and on the other that everything would be different if that experience had not happened to him: I think that if I hadn't gotten sick, I would have finished high school some time ago. The psychotic experience represented a significant and painful vital transformation, which does not fully integrate into his biographical continuity.

Finally, in relation to Future expectations, the story emphasizes Catastrophism:

P: Yes, but the difference is that I'm going to have to take these [medications] until I die... Yes, because I don't like the idea of having to take medications.

E: So, that is the most unpleasant change, if I understand you correctly...

P: Yes, because I think that when my son is mature, who is going to give me my medications, who is going to take care of me? Nobody, my father is going to be dead, my mother too, my sister, I suppose, is going to be married, and I don't want to have children but then who is going to give them to me, who is going to take care of me? Nobody.

According to the elements of the family context regarding FESZ, the expectations that B can have reveal a fundamentally catastrophic perspective of the future, mainly of adult life, in the absence of a life project that will enable him to go forward. This vision of the future also places a lot of emphasis on the medication that he will need, and his concerns about the care he will need as an adult: Who is going to take care of me? Nobody.

\section{Discussion}

The main results of the study argue that the phenomena of appropriation of FESZ (case A) and resistance to the appropriation of FESZ (case B), illustrate two opposite variants of the integration processes of psychotic experiences in the biographical weave. In order to deepen the scope of these results, we will briefly summarize the main aspects of each case.

In case A, the appropriation of FESZ favors a subjective experience of biographical continuity, by way of integrating the life transformation experiences. In this first case, there are three key elements that sustain the possibility of such an appropriation of the psychotic experience: the family's 
emotional climate linked to the onset of psychosis in the life of the son characterized as a chaotic and destabilizing transformation; the psychotherapeutic intervention developed in the day hospital; and active coping strategies deployed by the adolescent. It is interesting to emphasize that the family's emotional climate which surrounds the psychotic experience, despite its traumatic character, mobilizes and favors an active search for specialized professional help, in order to face and establish an action plan to support the son's recovery process. Furthermore, the psychotherapeutic intervention succeeds in hosting the questions regarding the meanings associated with living with schizophrenia in this case, queries which largely preceded the time when the diagnosis was made, favoring its elaboration. At this point, there seems to be an encounter between the questions of the adolescent about his psychotic experience and a therapeutic space that welcomes and enables its development, fostering the work of an autobiographical reconstruction post FESZ.

The resistance to the appropriation of FESZ in case B, however, reveals the construction of a story that testifies to the subjective experience of a biographical break in a complex and paradoxical operation that, at the same time, acknowledges the psychotic experience, refuses it and fails to successfully integrate the vital transformation experiences. In this case, the family's emotional climate of suffering seems to be linked to a conception of schizophrenia as a long-life disabling condition. Moreover, although the psychotherapeutic intervention in the day hospital tries to encourage the integration processes of psychotic experience and biographical reconstruction post FESZ, case B seems to settle into schizophrenia, living the experience as a tragic and unwanted story against which depressive affectivity dominates. In line with this, case B accounts for passive coping strategies, which, although they might be related to the feeling of having been scarcely included in the diagnostic process, also seem to account for his resistance to incorporate the experiences of vital transformation associated with the onset of psychosis.

Another important matter in which both cases may be contrasted is related to the future expectations associated to these two variants of integration of psychotic experiences in the biographical weave. In this regard, case A projects a future in line with previous expectations by adapting the requirements, while in case $\mathrm{B}$ a hopeless and catastrophic prospect of the future predominates. Such results, in agreement with the findings of previous studies, suggest that the higher the integration of the psychotic experience in the biographical continuity, the more hopeful the future projections (McGlashan \& Carpenter, 1981). But the question seems to be: if I incorporate the transformations associated with the psychotic experience into my life, what possible future can I anticipate? At this point, the family's and personal conceptions of a mental illness become highly relevant, particularly in relation to the pictured prospects of social reintegration: it is very different if FESZ appears as an event that can be actively confronted, or an experience that predicts a bleak future. As suggested by the results of MacDougall, Vandermeer, and Norman (2015), negative perceptions of the implications of the psychotic illness for the future increases the likelihood of depression. In this regard, the appropriation of FESZ seems to rely on future prospects that preserve some possibility of performing prior potentialities and expectations, or at least adapting to them in a tolerable way for the adolescents and their environment. In line with the suggestions of Lysaker et al. (2013) and MacDougall et al. (2015), such findings highlight the relevance of developing interventions that encourage more hopeful future perspectives for individuals facing a first psychotic episode and their families.

\section{Conclusions}

The work of an autobiographical reconstruction postFESZ appears as an active quest to maintain some sense of identity and hope and a sense of agency (Lysaker et al., 2013). The results emphasize the importance of addressing such work in the psychotherapeutic intervention and suggest the need to continue investigating the elements that favor and hinder this process. Our study is not conclusive about the reasons of such divergent accounts from one case to another, considering that both adolescents received psychotherapeutic support that tried to encourage the elaboration of the psychotic experience, which was even conducted by the same psychotherapist.

With regard to the methodological aspects, and taking into account the complex and multi-determined nature of the experiences of treatment and recovery processes from FESZ, it is relevant to reconstruct them from the perspective of all relevant participants (patients, relatives and clinicians). Their stories not only allow accessing rich descriptions of the elements and mechanisms that favor or hinder recovery processes, but also continuing to work on the visibility of the therapeutic and social needs of individuals with schizophrenia.

Regarding the limitations of the study, the number of participants was reduced and one of the cases had to do without the story of the mother, an aspect that limited the analysis of case B. In this regard, it is desirable that future research could go more in-depth into the exploration of recovery processes of people who have experienced FESZ in terms of an autobiographical continuity, and into the role that psychotherapeutic interventions play in these processes.

\section{References}

Abarzúa, M. (2010). Diagnóstico de primer episodio de esquizofrenia: trayectorias de adolescentes. Santiago: Universidad de Chile.

Albert, N., Bertelsen, M., Thorup, A., Petersen, L., Jeppesen, P., Le Quack, P., ..., Nordentoft, M. (2011). Predictors of recov- 
ery from psychosis. Analyses of clinical and social factors associated with recovery among patients with first-episode psychosis after 5 years. Schizophrenia Research, 125(2-3), 257-266. doi: 10.1016/j.schres.2010.10.013

American Psychiatric Association (2006). Practice guidelines for the treatment of psychiatric disorders: Comprehensive guidelines and guideline watches. Arlington, VA: American Psychiatric Association. doi: 10.1176/appi.books.9780890 423363.45859

Anthony, W.A. (1993). Recovery from mental illness: The guiding vision of the mental health service system in the 1990s. Psychosocial Rehabilitation Journal, 16(4), 11-23. doi: 10.1037/h0095655

Artigas, C., Cortés, R., \& Díaz, F. (2010). Hospital de Día: La producción de historia a partir del espacio institucional. $R e$ vista Castalia, 18, 25-32.

Barbato, A. (1998). Schizophrenia and public health. Geneva: Division of Mental Health and Prevention of Substance Abuse World Health Organization.

Braehler, C., \& Schwannauer, M. (2011). Recovering an emerging self: Exploring reflective function in recovery from adolescent-onset psychosis. Psychology and Psychotherapy: Theory, Research and Practice, 85(1), 48-67. doi: 10.1111/j.2044-8341.2011.02018.x

Davidson, L., \& Strauss, J.S. (1992). Sense of self in recovery from severe mental illness. British Journal of Medical Psychology, 65(2), 131-145. doi: 10.1111/j.2044-8341.1992.tb01693.x

Dixon, L., Dickerson, F., Bellack, A., Bennett, M., Goldberg, R., Lehman, A., ..., Tenhula, W. (2011). The schizophrenia patient outcomes research team psychosocial treatment recommendations USA 2009. International Clinical Psychopharmacology, 26, e61-e62. doi: 10.1097/01.yic.0000405737.66704.2c

Dixon, L., Perkins, D., \& Calmes, C. (2009). Guideline Watch (September 2009): Practice guideline for the treatment of patients with schizophrenia: Introduction. Arlington, VA: American Psychiatric Association. doi: 10.1176/appi.books.97808 90423929

Flanagan, E.H., Davidson, L., \& Strauss, J.S. (2010). The need for patient-subjective data in the DSM and the ICD. Psychiatry: Interpersonal and Biological Processes, 73(4), 297307. doi: $10.1521 /$ psyc.2010.73.4.297

Frese, F.J., Knight, E.L., \& Saks, E. (2009). Recovery from schizophrenia: With views of psychiatrists, psychologists, and others diagnosed with this disorder. Schizophrenia Bulletin, 35(2), 370-380. doi: 10.1093/schbul/sbn175

Gaebel, W., Riesbeck, M., \& Wobrock, T. (2011). Schizophrenia guidelines across the world: A selective review and comparison. International Review of Psychiatry, 23(4), 379-387. doi: 10.3109/09540261.2011.606801

Gleeson, J., Larsen, T., \& McGorry, P. (2003). Psychological treatment in pre- and early psychosis. The Journal of the American Academy of Psychoanalysis and Dynamic Psychiatry, 31(1), 229-245. doi: 10.1521/jaap.31.1.229.21933

Harder, S. (2006). Self-image and outcome in first-episode psychosis. Clinical Psychology \& Psychotherapy, 13(5), 285296. doi: 10.1002/cpp.498

Harder, S. (2007). The Danish National Schizophrenia project (DNS): Interpersonal self-image as predictor for outcome in first-episode psychosis (FEP). European Psychiatry, 22, S66. doi: 10.1016/j.eurpsy.2007.01.255

Jenkins, J.H., \& Carpenter-Song, E.A. (2008). Stigma despite recovery. Medical Anthropology Quarterly, 22(4), 381-409. doi: 10.1111/j.1548-1387.2008.00038.x
Karow, A., Naber, D., Lambert, M., \& Moritz, S. (2012). Remission as perceived by people with schizophrenia, family members and psychiatrists. European Psychiatry, 27(6), 426-431. doi: 10.1016/j.eurpsy.2011.01.013

Kennedy, J.L., Altar, C.A., Taylor, D.L., Degtiar, I., \& Hornberger, J.C. (2014). The social and economic burden of treatment-resistant schizophrenia. International Clinical Psychopharmacology, 29(2), 63-76. doi: 10.1097/yic.0b013e32836508e6

Knapp, M., Mangalore, R., \& Simon, J. (2004). The global costs of schizophrenia. Schizophrenia Bulletin, 30(2), 279-293. doi: 10.1093/oxfordjournals.schbul.a007078

Koenig, M., Castillo, M.-C., Blanchet, A., \& Bouleau, J.-H. (2011). Ce que nous apprennent les patients atteints de schizophrénie en rémission. Annales Médico-Psychologiques, Revue Psychiatrique, 169(3), 179-183. doi: 10.1016/j.amp.2011.02.001

Krause, M. (1995). La investigación cualitativa: Un campo de posibilidades y desafíos. Temas de Educación, 7, 19-39.

Kreyenbuhl, J., Buchanan, R.W., Dickerson, F.B., \& Dixon, L.B. (2010). The schizophrenia Patient Outcomes Research Team (PORT): Updated treatment recommendations 2009. Schizophrenia Bulletin, 36(1), 94-103. doi: 10.1093/ schbul/sbp 130

Kreyenbuhl, J., Slade, E.P., Medoff, D.R., Brown, C.H., Ehrenreich, B., Afful, J., ..., Dixon, L.B. (2011). Time to discontinuation of first- and second-generation antipsychotic medications in the treatment of schizophrenia. Schizophrenia Research, 131(1-3), 127-132. doi: 10.1016/j.schres. 2011.04.028

Kukla, M., Lysaker, P.H., \& Roe, D. (2014). Strong subjective recovery as a protective factor against the effects of positive symptoms on quality of life outcomes in schizophrenia. Comprehensive Psychiatry, 55(6), 1363-1368. doi: 10.1016/j. comppsych.2014.04.022

Larsen, J.A. (2004). Finding meaning in first episode psychosis: Experience, agency, and the cultural repertoire. Medical Anthropology Quarterly, 18(4), 447-471. doi: 10.1525/maq.2004. 18.4.447

Lehman, A.F., \& Steinwachs, D.M. (1998). Translating research into practice: The schizophrenia Patient Outcomes Research Team (PORT) treatment recommendations. Schizophrenia Bulletin, 24(1), 1-10. doi: 10.1093/oxfordjournals.schbul. a033302

Lieberman, P.B. (1989). "Objective" methods and "subjective" experiences. Schizophrenia Bulletin, 15(2), 267-275. doi: 10.1093/schbul/15.2.267

Lysaker, P.H., Glynn, S.M., Wilkniss, S.M., \& Silverstein, S.M. (2010). Psychotherapy and recovery from schizophrenia: A review of potential applications and need for future study. Psychological Services, 7(2), 75-91. doi: 10.1037/a0019115

Lysaker, P.H., Ringer, J., Maxwell, C., McGuire, A., \& Lecomte, T. (2010). Personal narratives and recovery from schizophrenia. Schizophrenia Research, 121(1-3), 271-276. doi: 10.1016/j.schres.2010.03.003

Lysaker, P.H., Vohs, J., Hillis, J.D., Kukla, M., Popolo, R., Salvatore, G., \& Dimaggio, G. (2013). Poor insight into schizophrenia: contributing factors, consequences and emerging treatment approaches. Expert Review of Neurotherapeutics, 13(7), 785-793. doi: 10.1586/14737175.2013.811150

MacDougall, A.G., Vandermeer, M.R.J., \& Norman, R.M.G. (2015). Negative future self as a mediator in the relationship between insight and depression in psychotic disorders. Schizophrenia Research, 165(1), 66-69. doi: 10.1016/j. schres.2015.03.035 
McGlashan, T.H. (1987). Recovery style from mental illness and long-term outcome. The Journal of Nervous and Mental Disease, 175(11), 681-685. doi: 10.1097/00005053-19871100000006

McGlashan, T.H., \& Carpenter, W.T. (1981). Does attitude toward psychosis relate to outcome? American Journal of Psychiatry, 138(6), 797-801. doi: 10.1176/ajp.138.6.797

McGorry, P., Killackey, E., \& Yung, A. (2007). Early intervention in psychotic disorders: detection and treatment of the first episode and the critical early stages. Medical Journal of Australia, 187(7), 8-10.

Ministry of Health (2000). Plan Nacional de Salud Mental y Psiquiatría. Santiago: Ministry of Health of Chile.

Ministry of Health (2009). Guía clínica para el tratamiento de personas desde primer episodio esquizofrenia. Santiago: Ministry of Health of Chile.

NICE (2014). Psychosis and schizophrenia in children and young people: Recognition and management. Manchester: National Institute for Health and Care Excellence.

Noiseux, S., \& Ricard, N. (2008). Recovery as perceived by people with schizophrenia, family members and health professionals: A grounded theory. International Journal of Nursing Studies, 45(8), 1148-1162. doi: 10.1016/j.ijnurstu.2007. 07.008

Penn, D.L., Waldheter, E.J., Perkins, D.O., Mueser, K.T., \& Lieberman, J.A. (2005). Psychosocial treatment for firstepisode psychosis: A research update. American Journal of Psychiatry, 162(12), 2220-2220. doi: 10.1176/appi.ajp.162. 12.2220

Republic of Chile (2004). Ley N ${ }^{\circ}$ 19966. Diario Oficial de la República de Chile, Santiago, Chile, 3 de septiembre de 2004. Available from: http://www.leychile.cl/N?i=229834 $\& \mathrm{f}=2004-09-03 \& \mathrm{p}$

Roe, D., \& Lachman, M. (2005). The subjective experience of people with severe mental illness: a potentially crucial piece of the puzzle. The Israel Journal of Psychiatry and Related Sciences, 42(4), 223-230.

Roe, D., Mashiach-Eizenberg, M., \& Lysaker, P.H. (2011). The relation between objective and subjective domains of recovery among persons with schizophrenia-related disorders. Schizophrenia Research, 131(1-3), 133-138. doi: 10.1016/j. schres.2011.05.023

Royal Australian and New Zealand College of Psychiatrists
(2005). Clinical practice guidelines for the treatment of schizophrenia and related disorders. Australian and New Zealand Journal of Psychiatry, 39(1-2), 1-30. doi: 10.1111/j. 1440-1614.2005.01516.x

Salvatore, G., Lysaker, P.H., Gumley, A., Popolo, R., Mari, J., \& Dimaggio, G. (2012). Out of illness experience: metacognition-oriented therapy for promoting self-awareness in individuals with psychosis. American Journal of Psychotherapy, 66(1), 85-106.

Seikkula, J., Alakare, B., \& Aaltonen, J. (2001). Open dialogue in psychosis. I: An introduction and case illustration. Journal of Constructivist Psychology, 14(4), 247-265. doi: 10.1080/ 107205301750433397

Silverstein, S.M., \& Bellack, A.S. (2008). A scientific agenda for the concept of recovery as it applies to schizophrenia. Clinical Psychology Review, 28(7), 1108-1124. doi: 10.1016 j.cpr.2008.03.004

Strauss, A., \& Corbin, J. (2002). Bases de la investigación cualitativa. Técnicas y procedimientos para desarrollar la teoría fundamentada. Medellín: Universidad de Antioquia.

Strauss, J.S. (1989). Subjective experiences of schizophrenia: Toward a new dynamic psychiatry-II. Schizophrenia Bulletin, 15(2), 179-187. doi: 10.1093/schbul/15.2.179

Thompson, K.N., McGorry, P.D., \& Harrigan, S.M. (2003). Recovery style and outcome in first-episode psychosis. Schizophrenia Research, 62(1-2), 31-36. doi: 10.1016/s0920-9964 (02)00428-0

Thornhill, H., Clare, L., \& May, R. (2004). Escape, enlightenment and endurance. Anthropology \& Medicine, 11(2), 181199. doi: $10.1080 / 13648470410001678677$

Weiden, P.J., Buckley, P.F., \& Grody, M. (2007). Understanding and treating "first-episode" schizophrenia. Psychiatric Clinics of North America, 30(3), 481-510. doi: 10.1016/j. psc.2007.04.010

Windell, D.L., Norman, R., Lal, S., \& Malla, A. (2014). Subjective experiences of illness recovery in individuals treated for first-episode psychosis. Social Psychiatry and Psychiatric Epidemiology, 50(7), 1069-1077. doi: 10.1007/s00127-0141006-x

Yip, K.-S. (2004). The importance of subjective psychotic experiences: Implications on psychiatric rehabilitation of people with schizophrenia. Psychiatric Rehabilitation Journal, 28(1), 48-54. doi: 10.2975/28.2004.48.54 